\title{
Short communication: Feed sorting of dairy heifers is influenced by method of dietary transition
}

\author{
E. K. Miller-Cushon, ${ }^{*}$ J. P. Vogel, $\nmid$ and T. J. DeVries $\dagger^{1}$ \\ *Department of Animal Sciences, University of Florida, Gainesville 32611 \\ †Department of Animal and Poultry Science, University of Guelph, Kemptville Campus, Kemptville, ON, K0G 1J0, Canada
}

\begin{abstract}
This study investigated the effect of exposing heifers to individual feed components on the extent and pattern of feed sorting upon transition to a novel ration. Holstein heifers (394 \pm 62 d old, weighing $409.8 \pm 37.3$ $\mathrm{kg}$; mean $\pm \mathrm{SD}$ ), consuming a familiar mixed silagebased ration [55\% corn silage and $45 \%$ haylage, dry matter (DM) basis], were transitioned to a novel total mixed ration [TMR; $41.6 \%$ haylage, $36.5 \%$ corn silage, $14.6 \%$ high-moisture corn, and $7.3 \%$ protein supplement, DM basis] by 1 of 2 treatments: direct transition to novel TMR (DIR; $\mathrm{n}=5$ ) or exposure to novel TMR components individually before receiving novel TMR (COM; $\mathrm{n}=6$ ). During the baseline period (d 1 to 4 ), all heifers were offered the familiar silage-based ration. During transition (d 5 to 12), DIR heifers received the novel TMR, whereas COM heifers received the novel TMR components offered separately, in amounts according to TMR composition (target $15 \%$ orts). After transition (d 13 to 20), all heifers received the novel TMR. Feed intake and feeding time were determined daily and fresh feed and individual orts were sampled every $2 \mathrm{~d}$ for particle size analysis and neutral detergent fiber content. The particle size separator consisted of 3 screens $(18,9$, and $1.18 \mathrm{~mm})$ and a bottom pan, resulting in 4 fractions (long, medium, short, and fine). Sorting activity for each fraction was calculated as actual intake expressed as a percentage of predicted intake. We detected no effect of treatment on dry matter intake or feeding time. After transition to the novel TMR, COM heifers sorted to a greater extent than did DIR heifers, sorting against long particles (95.4 vs. 98.9\%) and for short particles (101.7 vs. 100.6\%). Differences in sorting patterns resulted in COM heifers tending to have lower neutral detergent fiber intake as a percentage of predicted intake (98.9 vs. 100.5\%). The results of this study suggest that the degree of feed sorting may be influenced by method of transition to a novel ration.
\end{abstract}

Received August 25, 2014.

Accepted December 14, 2014.

${ }^{1}$ Corresponding author: tdevries@uoguelph.ca
Key words: feed sorting, dairy heifer, diet transition, feeding

\section{Short Communication}

Feed sorting by dairy cattle is of ongoing concern due to its effect on the nutrient composition of the ration consumed and, consequently, on rumen fermentation (DeVries et al., 2008) and milk fat production (Sova et al., 2013). Feed sorting behavior is typically addressed through feed management strategies applied at the herd level, such as adjusting ration DM content (Leonardi et al., 2005; Miller-Cushon and DeVries, 2009), feeding level (Miller-Cushon and DeVries, 2010), and feeding frequency (DeVries et al., 2005).

Considerable individual variability exists in the extent and pattern of feed sorting in both adult cattle (Leonardi and Armentano, 2003) and growing calves (Miller-Cushon et al., 2013b). Recent work has shown that differences in prior feed experiences can have persistent effects on feed sorting. For example, feed sorting in weaned dairy calves has been found to be influenced by prior exposure to different feed types (Miller-Cushon and DeVries, 2011), feed presentations (Miller-Cushon et al., 2013a), and ration forage particle sizes (Miller-Cushon et al., 2013b). Further, differences in feed sorting in weaned calves have been found to persist through transition to a novel TMR (Miller-Cushon et al., 2013a).

Dairy cattle undergo several dietary transitions at different stages of growth and lactation, yet it is unclear how feed experiences during transition to a novel diet influence the development or persistence of feed sorting. The objective of this study was to assess how the method of introducing a novel diet affects feed sorting in dairy heifers after transition to a novel TMR. We hypothesized that exposing heifers to individual ration components before offering a novel TMR would influence the extent of feed sorting for or against those ration components.

This study used 12 Holstein heifers (mean \pm SD) 394 $\pm 62 \mathrm{~d}$ of age, weighing $409.8 \pm 37.3 \mathrm{~kg}$ at the beginning of the experiment and $451.5 \pm 43.2 \mathrm{~kg}$ at the end 
of the experiment. Animals were housed, 6 at a time, at the University of Guelph Kemptville Campus Dairy Education and Research Centre (Kemptville, ON, Canada) in a $39.2-\mathrm{m}^{2}$ wood shaving bedded-pack pen, and were managed in accordance with the guidelines and policies set by the Canadian Council of Animal Care (CCAC, 2009) and the University of Guelph Animal Care Committee (AUP \#1913). Wood shaving bedding was removed and replenished twice weekly. Heifers had ad libitum access to water via a communal water bowl. All animals were given a free-choice mineral supplement. Feed was provided ad libitum amounts (target $15 \%$ orts) using roughage intake control feed bins (Insentec B.V., Marknesse, the Netherlands; Chapinal et al., 2007). Each heifer was assigned to and trained to eat exclusively from a single feed bin.

This study was conducted in 2 replicates, with 6 heifers tested in each replicate. Within each replicate, heifers were assigned to 1 of 2 treatments, balanced by age and weight: (1) exposure to TMR components individually and sequentially before receiving a novel TMR (COM), and (2) direct transition to the novel TMR without exposure to individual components (DIR). During the first $8 \mathrm{~d}$ of each replicate, heifers received a familiar silage-based ration (Table 1) and were allowed $4 \mathrm{~d}$ to acclimate to the pen and feed bins $(\mathrm{d}-4$ to -1$)$ before baseline measurements of feed sorting ( 1 to 4) were collected. During the dietary transition period (d 5 to 12), DIR heifers were offered the novel TMR, whereas COM heifers were introduced to the separate ration components of the novel TMR. Ration components were provided in proportions consistent with the formulation of the novel TMR, with offered amounts of ration components calculated based on total intake of individual heifers. Components were presented individually in the feed bins sequentially during each day, according to the feeding schedules described in Table 2 , with heifers rotating through all feeding schedules at 2-d intervals. As such, each heifer on the COM treatment was exposed to each of 4 feeding schedules for $2 \mathrm{~d}$ during the 8-d transition period. Before each feed was offered, remaining quantities of the previous feed type were weighed and removed. Feeding schedules (Table 2) were designed to partly randomize the order of exposure to ration components, while interspersing provision of high-forage and high-energy ration components to support rumen health. Greater time was allotted for consumption of forage components compared with protein supplement and high-moisture corn to account for differences in the quantity provided and expected rates of intake. From d 13 to 20, all heifers received the novel TMR (Table 1). Both rations provided during the study were formulated for a nonbred Holstein heifer to maintain $0.90 \mathrm{~kg} / \mathrm{d}$ of growth (NRC, 2001).
Table 1. Ingredient composition, chemical composition, ${ }^{1}$ and particle size distribution ${ }^{2}$ of diets

\begin{tabular}{|c|c|c|}
\hline \multirow[b]{2}{*}{ Composition } & \multicolumn{2}{|c|}{ Diet } \\
\hline & $\begin{array}{l}\text { Familiar } \\
\text { ration }\end{array}$ & $\begin{array}{l}\text { Novel } \\
\text { TMR }\end{array}$ \\
\hline \multicolumn{3}{|c|}{ Ingredient composition, $\%$ of DM } \\
\hline Corn silage ${ }^{3}$ & 55.0 & 36.5 \\
\hline Haylage $^{4}$ & 45.0 & 41.4 \\
\hline High-moisture corn ${ }^{5}$ & - & 13.8 \\
\hline Protein supplement ${ }^{6}$ & - & 8.3 \\
\hline \multicolumn{3}{|c|}{ Chemical composition, $\%$ of DM } \\
\hline $\mathrm{CP}$ & $13.6 \pm 1.4$ & $14.05 \pm 1.6$ \\
\hline $\mathrm{ADF}$ & $29.2 \pm 2.0$ & $23.6 \pm 0.55$ \\
\hline $\mathrm{NDF}$ & $45.0 \pm 2.2$ & $37.6 \pm 1.4$ \\
\hline $\mathrm{NFC}$ & $34.3 \pm 3.1$ & $38.9 \pm 0.35$ \\
\hline TDN & $62.1 \pm 1.2$ & $68.4 \pm 0.85$ \\
\hline \multicolumn{3}{|c|}{ Particle size distribution, $\%$ of DM } \\
\hline Long & $16.8 \pm 5.1$ & $14.0 \pm 4.4$ \\
\hline Medium & $44.5 \pm 2.3$ & $39.6 \pm 1.6$ \\
\hline Short & $31.6 \pm 3.3$ & $35.4 \pm 2.4$ \\
\hline Fine & $7.1 \pm 1.3$ & $11.0 \pm 2.0$ \\
\hline
\end{tabular}

${ }^{1}$ Values were obtained from chemical analysis of TMR samples. OM $=100-\%$ ash $; \mathrm{NFC}=100-(\% \mathrm{CP}+\% \mathrm{NDF}+\%$ fat $+\%$ ash $)$.

${ }^{2}$ Particle size was determined by a Penn State Particle Separator, which has a 19-mm screen (long), 8-mm screen (medium), 1.18-mm screen (short), and a pan (fine).

${ }^{3}$ Corn silage had a DM of $40.7 \pm 3.7 \%$ and chemical composition (DM basis) of $8.0 \pm 0.2 \% \mathrm{CP}, 19.6 \pm 1.7 \%$ ADF, $34.8 \pm 1.9 \% \mathrm{NDF}$, and $74.5 \pm 1.0 \%$ TDN. Particle size (determined by a Penn State Particle Separator) distribution of corn silage (DM basis) was $11.0 \pm 4.1 \%$ long, $48.2 \pm 3.1 \%$ medium, $35.8 \pm 2.4 \%$ short, and $4.9 \pm 1.5 \%$ fine.

${ }^{4}$ Haylage had a DM of $56.1 \pm 7.3 \%$ and chemical composition (DM basis) of $16.0 \pm 2.5 \% \mathrm{CP}, 35 \pm 2.8 \% \mathrm{ADF}, 49.2 \pm 1.3 \% \mathrm{NDF}$, and 57.1 $\pm 2.2 \%$ TDN. Particle size distribution of alfalfa haylage (DM basis) was $16.2 \pm 5.0 \%$ long, $45.0 \pm 3.2 \%$ medium, $30.7 \pm 3.5 \%$ short, and $8.1 \pm 2.5 \%$ fine.

${ }^{5}$ High-moisture corn had a DM of $80.6 \pm 0.9 \%$ and a chemical composition (DM basis) of $9.0 \pm 0.2 \% \mathrm{CP}, 4.0 \pm 0.29 \% \mathrm{ADF}, 12.4 \pm 1.9 \%$ $\mathrm{NDF}$, and $86.8 \pm 0.8 \%$ TDN.

${ }^{6}$ Supplied by Dundas Feed \& Seed Ltd. (Dundas, Ontario, Canada), containing (on as-is basis): $35 \%$ wheat shorts, $18 \%$ canola meal, $15 \%$ corn distillers, $13.5 \%$ wheat, $10 \%$ barley, $2.8 \%$ calcium carbonate, $2 \%$ cane molasses, $2 \%$ corn gluten meal, $1 \%$ pelleting agent, $0.62 \%$ salt, $0.04 \%$ trace minerals, $0.025 \%$ flavor, and $0.015 \%$ vitamins.

Throughout the study, the automated feed bins (Insentec B.V.) continuously measured individual feed intakes and feeding time. For determination of diet DM and nutrient content, representative samples of fresh feed and orts were taken on d 1, 5, 9, 13, and 17 of each replicate. To assess baseline sorting activity of the familiar silage-based ration, fresh feed and orts were sampled on $\mathrm{d}-1,2$, and 4 . To assess sorting activity during the dietary transition period, fresh feed and orts samples were taken on d 6,8,10, and 12 of the TMR for heifers on the DIR treatment and of corn silage and haylage for COM heifers. To assess sorting activity after dietary transition, fresh and orts samples were taken of the novel TMR for all heifers on $\mathrm{d} 14,16,18$, and 20. Samples taken for DM and chemical analysis were oven-dried at $55^{\circ} \mathrm{C}$ for $48 \mathrm{~h}$ and then ground through a 
Table 2. Feeding schedule for offering novel TMR components to heifers (COM treatment) during the dietary transition period (d 5-12) ${ }^{1}$

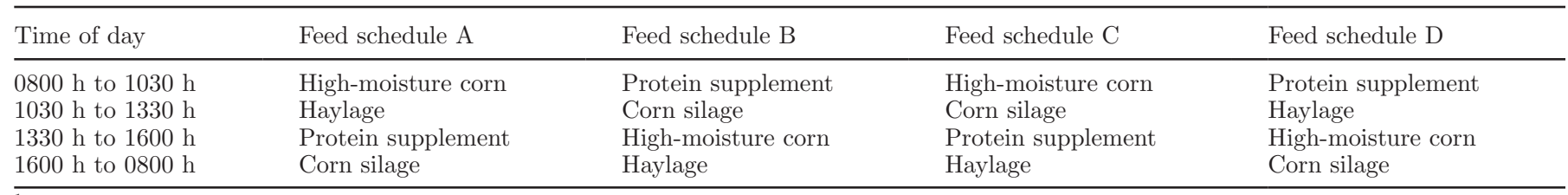

${ }^{1}$ COM heifers $(n=6)$ were rotated through each feeding schedule at 2-d intervals, such that each heifer received feed components according to each schedule twice.

1-mm screen (Brinkmann Mill, Brinkman Instruments Co., Westbury, NY). These samples were then pooled by feed type and replication and sent to Cumberland Valley Analytical Services Inc. (Maugansville, MD) for analysis of $\mathrm{DM}\left(135^{\circ} \mathrm{C}\right.$; AOAC International, 2000; method 930.15), ash $\left(535^{\circ} \mathrm{C}\right.$; AOAC International, 2000; method 942.05), ADF (AOAC International, 2000; method 973.18), NDF with heat-stable $\alpha$-amylase and sodium sulfite (Van Soest et al., 1991), and CP $(\mathrm{N} \times 6.25$; AOAC International, 2000; method 990.03; Leco FP-528 Nitrogen Analyzer, Leco, St. Joseph, MI). Samples taken for particle size analysis were separated using the 3 -screen $(19,8$, and $1.18 \mathrm{~mm})$ Penn State Particle Separator (PSPS; Kononoff et al., 2003).

Sorting was calculated as the actual intake of each fraction of the PSPS expressed as a percentage of the predicted intake of that fraction (Leonardi and Armentano, 2003). Predicted intake of a fraction was calculated as the product of the DMI of the total diet multiplied by the DM percentage of the fraction in the fed feed. Values equal to $100 \%$ indicated no sorting, values $<100 \%$ indicated selection against, and values $>100 \%$ indicated preferential sorting (sorting for) for a particular fraction. Data for sorting activity, DMI, and feeding time were averaged by heifer across period (baseline, d 1 to 4; transition, d 5 to 12; after transition, d 13 to 20). During the dietary transition period, DMI, feeding time, and feed sorting were summarized separately by feed type for COM heifers.

One heifer (DIR) did not learn how to use the automated feed bin correctly and so was removed from the trial. Thus, data were collected for $\mathrm{n}=5$ DIR heifers and $\mathrm{n}=6 \mathrm{COM}$ heifers. Before the study, a power analysis (Morris, 1999) was performed for the primary response variable, sorting. Estimates for variation of sorting were based on previously reported values for sorting of the long particle fraction in weaned calves and heifers, because sorting of this fraction is typically subject to greatest variability (Greter et al., 2010; Miller-Cushon et al., 2013a). Based on the power analysis, it was expected that at $80 \%$ power, treatment differences of $10 \%$ would be detected at this sample size.

Extent of sorting of each fraction of the PSPS was analyzed within treatment and period (and feed type, for COM heifers during the dietary transition period) and tested for a difference from 100 using $t$-tests (PROC TTEST; SAS Institute, 2009). During the dietary transition period, DMI of separate feed components, as a percentage of total DMI, by COM heifers were analyzed for a difference from the percentage contribution of each ingredient to the novel TMR using $t$-tests. For heifers fed COM, differences in feeding time, rate of intake, and feed sorting between feed components were assessed within heifer using dependent-group $t$-tests (SAS Institute, 2009). The effect of treatment on total DMI and feeding time during and after dietary transition was assessed using the MIXED procedure of SAS (SAS Institute, 2009), treating period as a repeated measure, with a model that included the fixed effects of treatment, period, treatment $\times$ period interaction, and the random effects of replicate and heifer within treatment and replicate. Compound symmetry was selected as the covariance structure based on best fit according to Schwarz's Bayesian information criterion. The extent of sorting was compared between treatments only after transition to the novel TMR (d 13 to 20). This was assessed using the MIXED procedure of SAS (SAS Institute, 2009) using a model that included the fixed effects of treatment with baseline sorting values (average values obtained in $\mathrm{d} 1$ to 4 ) included as a covariate and the random effects of replicate and heifer within treatment and replicate. All values reported are least squares means. Significance was declared at $P \leq 0.05$ and trends reported if $0.05<P \leq 0.10$.

We detected no effect of dietary transition on DMI throughout the study ( $\mathrm{SE}=0.42 ; P=0.31$ ), with COM heifers having similar DMI to DIR heifers during the dietary transition period, when ration components were offered separately rather than as a TMR (12.3 vs $12.1 \mathrm{~kg} / \mathrm{d}$ ) and during the final period of exposure to the novel TMR (13.4 vs $13.0 \mathrm{~kg} / \mathrm{d}$ ). As intended, the intakes of individual ration components by COM heifers during the dietary transition period, as a percentage of DMI (Table 3), did not differ $(P>0.3)$ from the ingredient composition of the novel TMR (described in Table 1). Differences in feed presentation, as during the dietary transition period, have not been found to influence intake in lactating cattle (Maekawa et al., 
Table 3. Feeding behavior (mean $\pm \mathrm{SE}$ ) during dietary transition period ( $\mathrm{d} 5$ to 12 ) to novel TMR, by heifers offered novel TMR components separately $(\mathrm{COM})^{1}$

\begin{tabular}{lcccc}
\hline Item & Haylage & Corn silage & $\begin{array}{c}\text { High-moisture } \\
\text { corn }\end{array}$ & $\begin{array}{c}\text { Protein } \\
\text { supplement }\end{array}$ \\
\hline DMI, $\mathrm{kg} / \mathrm{d}$ & $5.0 \pm 0.52$ & $4.7 \pm 0.26$ & $1.72 \pm 0.16$ & $1.05 \pm 0.057$ \\
DMI, \% of total & $42.4 \pm 1.4$ & $35.4 \pm 1.3$ & $13.9 \pm 0.8$ & $8.6 \pm 0.23$ \\
Feeding time, min/d & $86.0 \pm 9.8^{\mathrm{a}}$ & $78.7 \pm 9.3^{\mathrm{a}}$ & $13.1 \pm 1.7^{\mathrm{b}}$ & $7.3 \pm 0.67^{\mathrm{b}}$ \\
Rate of intake, g/min & $76.2 \pm 7.2^{\mathrm{a}}$ & $62.9 \pm 4.6^{\mathrm{a}}$ & $162.4 \pm 2.8^{\mathrm{b}}$ & $168.3 \pm 2.7^{\mathrm{b}}$ \\
Sorting of particle size fraction, ${ }^{2} \%$ & & & - \\
Long & $99.8 \pm 3.4^{\mathrm{a}}$ & $87.6 \pm 2.4^{\mathrm{b} * *}$ & - & - \\
Medium & $96.4 \pm 0.79^{\mathrm{a} * *}$ & $100.9 \pm 0.28^{\mathrm{b} *}$ & - & - \\
Short & $100.3 \pm 0.72^{\mathrm{a}}$ & $102.9 \pm 0.94^{\mathrm{b} *}$ & - & - \\
Fine & $108.6 \pm 2.3^{\mathrm{a} *}$ & $95.6 \pm 4.4^{\mathrm{b}}$ & - & - \\
\hline
\end{tabular}

${ }^{\mathrm{a}, \mathrm{b}}$ Values within rows without a common superscript differ $(P<0.05)$.

${ }^{1}$ Data were averaged over an 8-d dietary transition period for 6 heifers on the COM treatment.

${ }^{2}$ Sorting $\%=100 \times$ (actual nutrient or particle size fraction DM intake/predicted nutrient or particle size fraction DM intake). Values equal to $100 \%$ indicate no sorting, $<100 \%$ indicate selective refusals (sorting against), and $>100 \%$ indicate preferential consumption (sorting for). Data are averaged over $8 \mathrm{~d}$ of period. Particle size determined by Penn State Particle Separator, which separates the particles in 4 fractions: long $(>19 \mathrm{~mm})$, medium $(<19,>8 \mathrm{~mm})$, short $(<8,>1.18 \mathrm{~mm})$, and fine $(<1.18 \mathrm{~mm})$. For COM heifers from d 5 to 12 , sorting was assessed only for haylage and corn silage feed components. ${ }^{* *} P \leq 0.01,{ }^{*} P \leq 0.05$ : difference in sorting values from $100 \%$.

2002), heifers (DeVries and von Keyserlingk, 2009), or calves (Miller-Cushon et al., 2013a). Intake of the novel TMR during the final period of exposure was not influenced by previous experience (i.e., during the dietary transition period). Similarly, results from previous studies suggest that, whereas feed preferences may be greatly influenced by previous experience, total intake is relatively resilient (Arnold and Maller, 1977). For example, dairy calves offered a mixed diet had similar total intakes, regardless of previous experience receiving feed components either separately or as a mixture (Miller-Cushon et al., 2013b).

Overall feeding time was not influenced by method of dietary transition $(\mathrm{SE}=12.0 ; P=0.80)$, with $\mathrm{COM}$ heifers having similar feeding times to DIR heifers during transition, when ration components were offered separately rather than as a TMR (169.5 vs 187.0 $\mathrm{min} / \mathrm{d}$ ), and during the final period of novel TMR exposure (174.9 vs $186.0 \mathrm{~min} / \mathrm{d})$. In contrast, heifers offered feed ingredients either as separate components or unmixed with the grain component and top-dressed on the forage have been found to have reduced feeding times and greater rates of intake compared with heifers offered a TMR (DeVries and von Keyserlingk, 2009; Greter et al., 2010). In those studies, greater rates of intake were explained by rapid consumption of the concentrate component of the ration at the time of delivery before consumption of the forage component. Overall feeding time might have been similarly influenced in the present study if different ration components were provided simultaneously or if competitive pressure had been a factor (Greter et al., 2010). Although total time spent feeding was similar between treatments during the dietary transition period, heifers fed COM consumed high-moisture corn and protein supplement much more rapidly than corn silage and haylage and, as result of differences in offered quantities and rates of intake, spent less time consuming these feeds (Table 3 ).

Before imposing dietary transition treatments, little sorting of the familiar silage-based TMR occurred; although heifers tended to sort against the medium particle size fraction $(99.08 \pm 0.46 \%, P=0.09)$, we observed no sorting $(P>0.1)$ of the long $(100.7 \pm$ $2.0 \%)$, short $(100.4 \pm 0.67 \%)$, or fine $(102.3 \pm 1.3 \%)$ particle size fractions. During the dietary transition period, heifers that were transitioned directly to the novel TMR tended $(P<0.1)$ to sort against long particles $(96.6 \pm 1.6)$ and sort for short particles $(101.3 \pm 0.58)$, but did not sort for or against medium particles (99.8 $\pm 0.21)$ or fine particles $(100.8 \pm 0.47)$. In comparison, heifers that were exposed to ration components separately sorted the haylage and corn silage components extensively, selecting against medium haylage particles and for fine haylage particles, and selecting against long corn silage particles and for medium and short corn silage particles (Table 3). The extent of sorting of corn silage and haylage by heifers fed COM was surprising, given the minimal sorting of the familiar silage-based TMR (containing corn silage and haylage) observed during the baseline period. Increased sorting of these components during the dietary transition period may have been facilitated by provision of smaller quantities of feed when ration components were provided individually. We can also speculate that sorting of the corn silage and haylage components by $\mathrm{COM}$ heifers during the dietary transition period was influenced by expo- 
sure at other times of the day to the high-moisture corn and protein supplement. For example, if high-moisture corn were perceived as highly palatable (due to high starch content, and a sweet flavor; Nombekela et al., 1994), heifers may have been motivated to maintain intake of smaller, more palatable particles when they received their allotment of corn silage and consequently sorted in favor of the short particle fractions.

Sorting differed between treatments once all heifers were offered the novel TMR (Table 4). Whereas heifers transitioned to the TMR directly maintained minimal sorting (only tending to sort against long particles), heifers transitioned to the novel TMR via exposure to individual components sorted against long particles and sorted for short particles to a greater extent. Thus, compared with direct transition, exposure to individual ration components increased sorting of the novel ration. The difference in sorting of the novel TMR may be explained by behavior during the dietary transition period. Heifers offered separate components sorted haylage and, in particular, corn silage against long particles and in favor of shorter particles. This pattern of sorting behavior appears to have persisted upon transition to the novel TMR, as those heifers continued to sort against long particles and for short particles to a greater extent during the week after transition. In a general sense, these results support the idea that prior opportunity to sort feed may be a factor influencing the extent of feed sorting. In calves, exposure to feed factors before weaning that encouraged greater sorting (such as feed presentation, Miller-Cushon et al., 2013a; and forage particle size, Miller-Cushon et al., 2013b) have been found to result in persistently greater sorting in the weeks after weaning. Further, differences in sorting resulting from early experience have been found to persist after transition to a novel ration in calves (Miller-Cushon et al., 2013a). The present results suggest that even short-term differences in feed experience during transition to a novel ration can influence the extent of feed sorting of a novel ration, at least in the initial week after transition. Further work is encouraged to investigate the persistence of individual differences in extent and pattern of sorting, as well as the biological significance of feed sorting in growing heifers. For example, Greter et al. (2010) reported that increased selection against forage did not affect growth but was associated with looser stools, indicating reduced rumen $\mathrm{pH}$ (Krause and Oetzel, 2006). However, it is not clear at what level differences in extent of sorting may negatively affect rumen health.

Patterns of feed sorting are influenced by feed factors such as particle size (Montoro et al., 2013; Khan et al., 2014) and palatability of ration components (Miller-Cushon et al., 2014). As such, feed properties may influence patterns of feed sorting that arise during transition to a novel ration. In the present study, increased sorting of the short particle fraction of the novel TMR by COM heifers is consistent with selection in favor of the protein supplement and high-moisture corn, ration components that are generally considered palatable for cattle. It is possible that exposure to highmoisture corn and the protein supplement individually resulted in the development of preferences for those components, which may have motivated increased sorting of the novel TMR.

In conclusion, this study demonstrated that the method of transitioning heifers to a novel TMR has potential to affect the extent of feed sorting. Heifers

Table 4. Effect of method of dietary transition to a novel TMR $(\mathrm{COM} \text { or DIR })^{1}$ on feed sorting after transition $(\mathrm{d} 13-20)^{2}$

\begin{tabular}{lcccc}
\hline & \multicolumn{2}{c}{ Treatment } & & \\
\cline { 2 - 3 } Value & COM & DIR & SE & $P$-value \\
\hline Sorting of particle size, ${ }^{3} \%$ & & & & \\
$\quad$ Long & $95.4^{* *}$ & $98.7^{\dagger}$ & 0.52 & $<0.001$ \\
Medium & $99.3^{*}$ & 99.6 & 0.22 & 0.45 \\
Short & $101.7^{* *}$ & 100.6 & 0.36 & 0.038 \\
Fine & $102.4^{*}$ & 100.7 & 1.0 & 0.090 \\
NDF intake, \% of predicted intake & $98.9 \dagger$ & 100.5 & 0.63 & 0.067 \\
\hline
\end{tabular}

${ }^{1} \mathrm{COM}=$ heifers exposed to separate feed components before receiving novel TMR; DIR $=$ heifers transitioned directly to novel TMR.

${ }^{2}$ Data are averaged across an 8-d period after dietary transition for each heifer/treatment $(\mathrm{n}=6$ for COM, $\mathrm{n}$ $=5$ for DIR).

${ }^{3}$ Sorting $\%=100 \times$ (actual particle size fraction DM intake/predicted particle size fraction DM intake). Values equal to $100 \%$ indicate no sorting, $<100 \%$ indicate selective refusals (sorting against), and $>100 \%$ indicate preferential consumption (sorting for). Data are averaged over $8 \mathrm{~d}$ of period. Particle size was determined using the Penn State Particle Separator, which separates the particles in 4 fractions: long $(>19 \mathrm{~mm})$, medium $(<19$, $>8 \mathrm{~mm})$, short $(<8,>1.18 \mathrm{~mm})$, and fine $(<1.18 \mathrm{~mm})$.

${ }^{* *} P \leq 0.01,{ }^{*} P \leq 0.05, \dagger P \leq 0.1$ : difference in sorting values from $100 \%$. 
transitioned to the novel TMR via sequential exposure to allotments of individual ration components sorted the corn silage and haylage components extensively during the dietary transition period and, after transition, sorted the novel TMR to a greater extent than did heifers transitioned to the novel TMR directly.

\section{ACKNOWLEDGMENTS}

We thank the staff and students at the University of Guelph, Kemptville Campus Dairy Education and Research Centre (Kemptville, ON, Canada). In particular, we thank Megan Bruce, Morgan Overvest, and Albert Koekkoek for their technical assistance. We also acknowledge funding support received from the Natural Sciences and Engineering Research Council of Canada (NSERC, Ottawa, ON, Canada) Discovery Grant (T. J. DeVries).

\section{REFERENCES}

AOAC International. 2000. Official Methods of Analysis. Vol. I. 17th ed. AOAC International, Arlington, VA.

Arnold, G. W., and R. A. Maller. 1977. Effects of nutritional experience in early and adult life on the performance and dietary habits of sheep. Appl. Anim. Ethol. 3:5-26.

CCAC. 2009. Guidelines on: The care and use of farm animals in research, teaching and testing. Canadian Council on Animal Care, Ottawa, ON, Canada.

Chapinal, N., D. M. Veira, D. M. Weary, and M. A. G. von Keyserlingk. 2007. Technical note: Validation of a system for monitoring individual feeding and drinking behavior and intake in grouphoused cattle. J. Dairy Sci. 90:5732-5736.

DeVries, T. J., F. Dohme, and K. A. Beauchemin. 2008. Repeated ruminal acidosis challenges in lactating dairy cows at high and low risk for developing acidosis: Feed sorting. J. Dairy Sci. 91:39583967.

DeVries, T. J., and M. A. G. von Keyserlingk. 2009. Short communication: Feeding method affects the feeding behavior of growing dairy heifers. J. Dairy Sci. 92:1161-1168.

DeVries, T. J., M. A. G. von Keyserlingk, and K. A. Beauchemin. 2005. Frequency of feed delivery affects the behavior of lactating dairy cows. J. Dairy Sci. 88:3553-3562.

Greter, A. M., K. E. Leslie, G. J. Mason, B. W. McBride, and T. J. Devries. 2010. Effect of feed delivery method on the behavior and growth of dairy heifers. J. Dairy Sci. 93:1668-1676.

Khan, M. A., A. Bach, Ll. Castells, D. M. Weary, and M. A. G. von Keyserlingk. 2014. Effects of particle size and moisture levels in mixed rations on the feeding behavior of dairy heifers. Animal $8: 1722-1727$
Kononoff, P. J., A. J. Heinrichs, and D. R. Buckmaster. 2003. Modification of Penn State forage and total mixed ration particle separator and the effects of moisture content on its measurement. J. Dairy Sci. 86:1858-1863.

Krause, K., and G. Oetzel. 2006. Understanding and preventing subacute ruminal acidosis in dairy herds: A review. Anim. Feed Sci. Technol. 126:215-236.

Leonardi, C., and L. E. Armentano. 2003. Effect of quantity, quality, and length of alfalfa hay on selective consumption by dairy cows. J. Dairy Sci. 86:557-564.

Leonardi, C., F. Giannico, and L. E. Armentano. 2005. Effect of water addition on selective consumption (sorting) of dry diets by dairy cattle. J. Dairy Sci. 88:1043-1049.

Maekawa, M., K. A. Beauchemin, and D. A. Christensen. 2002. Effect of concentrate level and feeding management on chewing activities, saliva production, and ruminal $\mathrm{pH}$ of lactating dairy cows. J. Dairy Sci. 85:1165-1175.

Miller-Cushon, E. K., R. Bergeron, K. E. Leslie, G. J. Mason, and T. J. Devries. 2013a. Effect of early exposure to different feed presentations on feed sorting of dairy calves. J. Dairy Sci. 96:4624-4633.

Miller-Cushon, E. K., and T. J. DeVries. 2009. Effect of dietary dry matter concentration on the sorting behavior of lactating dairy cows fed a total mixed ration. J. Dairy Sci. 92:3292-3298.

Miller-Cushon, E. K., and T. J. DeVries. 2010. Feeding amount affects the sorting behavior of lactating dairy cows. Can. J. Anim. Sci. 90:1-7.

Miller-Cushon, E. K., and T. J. DeVries. 2011. Effect of early feed type exposure on diet-selection behavior of dairy calves. J. Dairy Sci. 94:342-350.

Miller-Cushon, E. K., C. Montoro, A. Bach, and T. J. DeVries. 2013b. Effect of early exposure to mixed rations differing in forage particle size on feed sorting of dairy calves. J. Dairy Sci. 96:3257-3264.

Miller-Cushon, E. K., M. Terré, T. J. DeVries, and A. Bach. 2014. The effect of palatability of protein source on dietary selection in dairy calves. J. Dairy Sci. 97:4444-4454.

Montoro, C., E. K. Miller-Cushon, T. J. DeVries, and A. Bach. 2013. Effect of physical form of forage on performance, feeding behavior, and digestibility of Holstein calves. J. Dairy Sci. 96:1117-1124.

Morris, T. R. 1999. Experimental Design and Analysis in Animal Sciences. CABI Publishing, New York, NY.

NRC. 2001. Nutrient Requirements for Dairy Cattle. 7th rev. ed. Natl. Acad. Sci. Washington, DC.

Nombekela, S. W., M. R. Murphy, H. W. Gonyou, and J. I. Marden. 1994. Dietary preferences in early lactation cows as affected by primary tastes and some common feed flavors. J. Dairy Sci. $77: 2393-2399$.

SAS Institute. 2009. SAS User's Guide. Ver. 9.2. SAS Inst. Inc., Cary, NC.

Sova, A. D., S. J. LeBlanc, B. W. McBride, and T. J. DeVries. 2013. Associations between herd-level feeding management practices, feed sorting, and milk production in freestall dairy farms. J. Dairy Sci. 96:4759-4770.

Van Soest, P. J., J. B. Robertson, and B. A. Lewis. 1991. Methods for dietary fiber, neutral detergent fiber and nonstarch polysaccharide in relation to animal nutrition. J. Dairy Sci. 74:3583-3597. 